\title{
Targeted miRNA Profiling in Gastric Cancer with Clinical Assessment
}

\author{
Hikmet Pehlevan Özel ${ }^{1}$, Tolga Dinç ${ }^{2}$, Rafed Sait Tiryaki ${ }^{3}$, Ayşe Gökçe Keşküş̧, Özlen \\ $\mathrm{Konu}^{3}$, Selami Ilgaz Kayılı̆̆ lu ${ }^{4}$, and Faruk Coşkun ${ }^{1}$
}

\author{
${ }^{1}$ Ankara City Hospital \\ ${ }^{2}$ Affiliation not available \\ ${ }^{3}$ Bilkent University \\ ${ }^{4}$ Muğla Sitkı Koçman University
}

January 13, 2021

\begin{abstract}
Background The purpose of this study was to determine the alterations of a specific set of miRNA levels in gastric adenocarcinoma tissues in order to identify gastric cancer specific miRNAs. Identification of the relationship between alteration of miRNA expressions and clinical features of these gastric cancer patients was set as a secondary outcome. Material and Methods Gastric adenocarcinoma and normal stomach tissue samples of 20 patients who underwent surgery for gastric cancer were studied. miRNA expression profiling was performed for 8 miRNAs ( 2 of which has not been studied in detail for gastric cancer) in a total of 40 tissue samples using Quantitative Reverse Transcription Polymerase Chain Reaction. Alterations in expressions were compared with the clinicopathological characteristics of the patients. Results Five out of eight miRNAs were underexpressed in malignant tissues. A decrease in the expression levels of miR-375-3p, miR-196a-5p, miR-376c-3p, miR-34c-5p, and miR-767-5p were observed. Furthermore, the expression of miR-662 was reversely related with age (r: -0,44, p: 0.04933); miR-129-3p and miR34c-5p levels were correlated with an increase in the number of metastatic lymph nodes ( $\mathrm{r}: 0,47, \mathrm{p}: 0.036495 ; \mathrm{r}: 0,51$, p: 0.020289); and miR-376c-3p levels were negatively associated with smoking (p: 0.04321). In addition, the variability of miRNA expression in cancerous tissues was lower than that in normal tissues. Conclusion Alterations in miRNA expressions in gastric adenocarcinoma tissues compared to healthy tissues of each individual may serve as a starting point for research and development of a diagnostic tool for gastric cancer.
\end{abstract}

\section{Hosted file}

3.main manuscript.pdf available at https://authorea.com/users/389235/articles/503837targeted-mirna-profiling-in-gastric-cancer-with-clinical-assessment

\section{Hosted file}

4.Tables.pdf available at https://authorea.com/users/389235/articles/503837-targeted-mirnaprofiling-in-gastric-cancer-with-clinical-assessment 


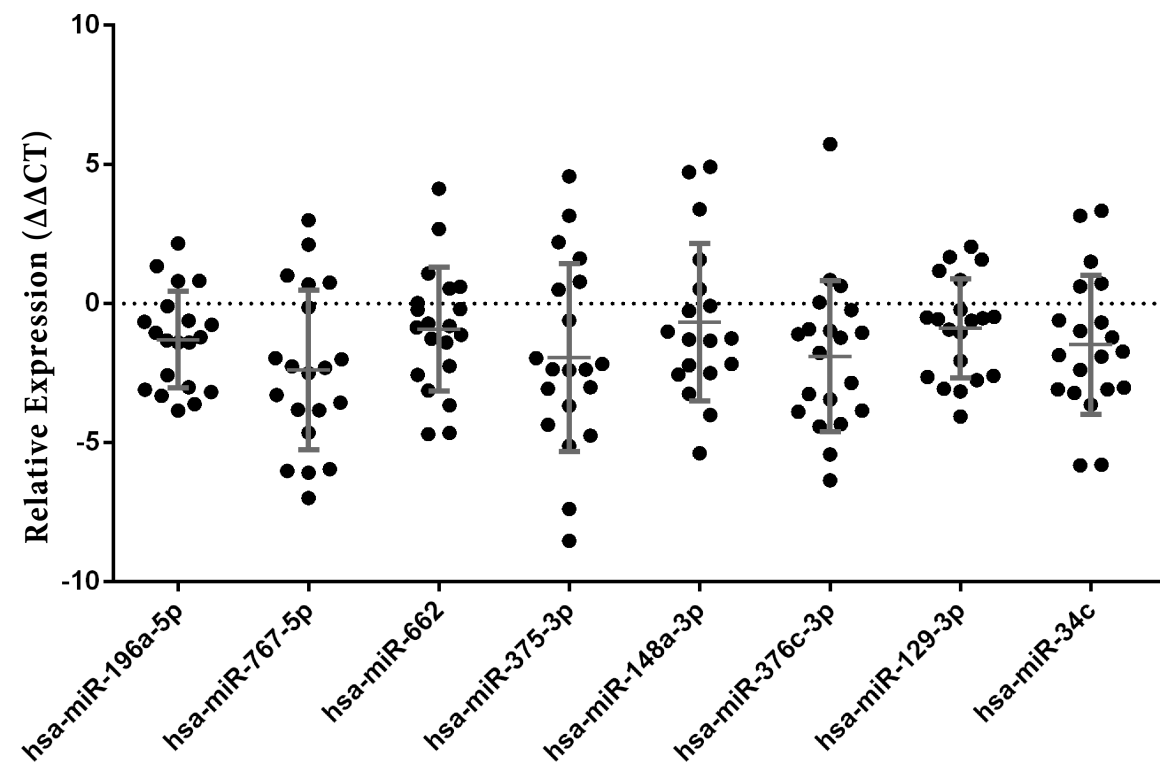

A

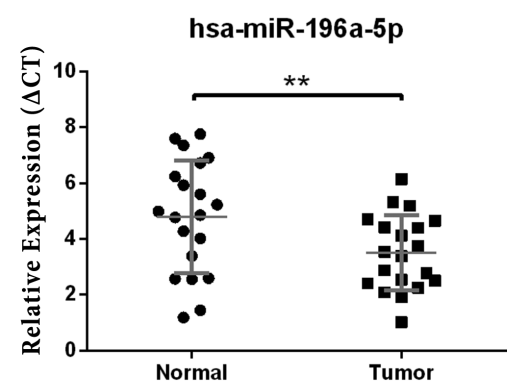

C

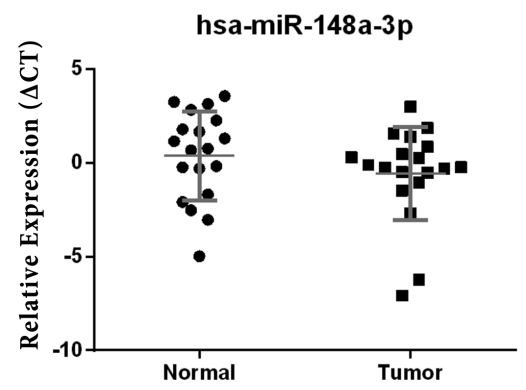

B

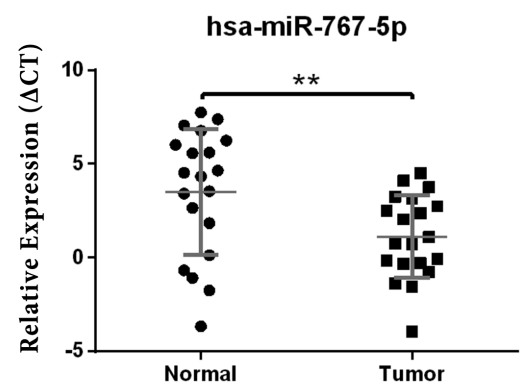

D

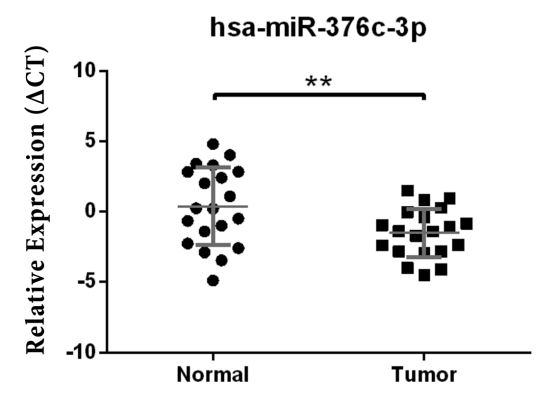


E

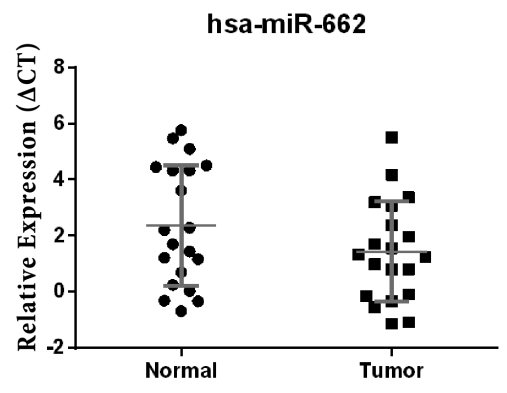

G

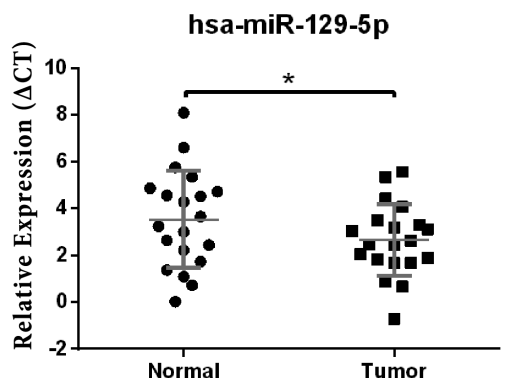

F

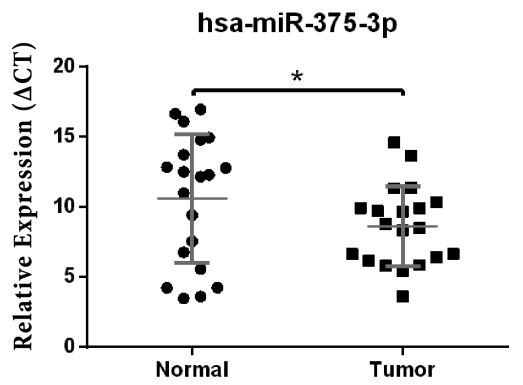

H

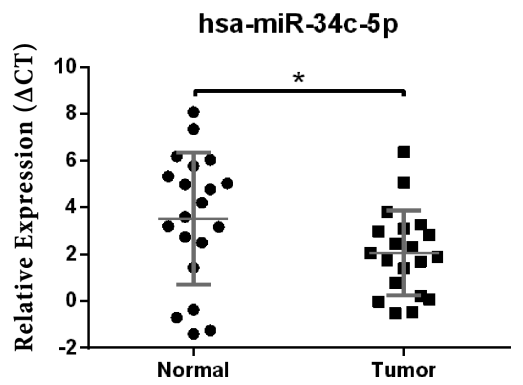

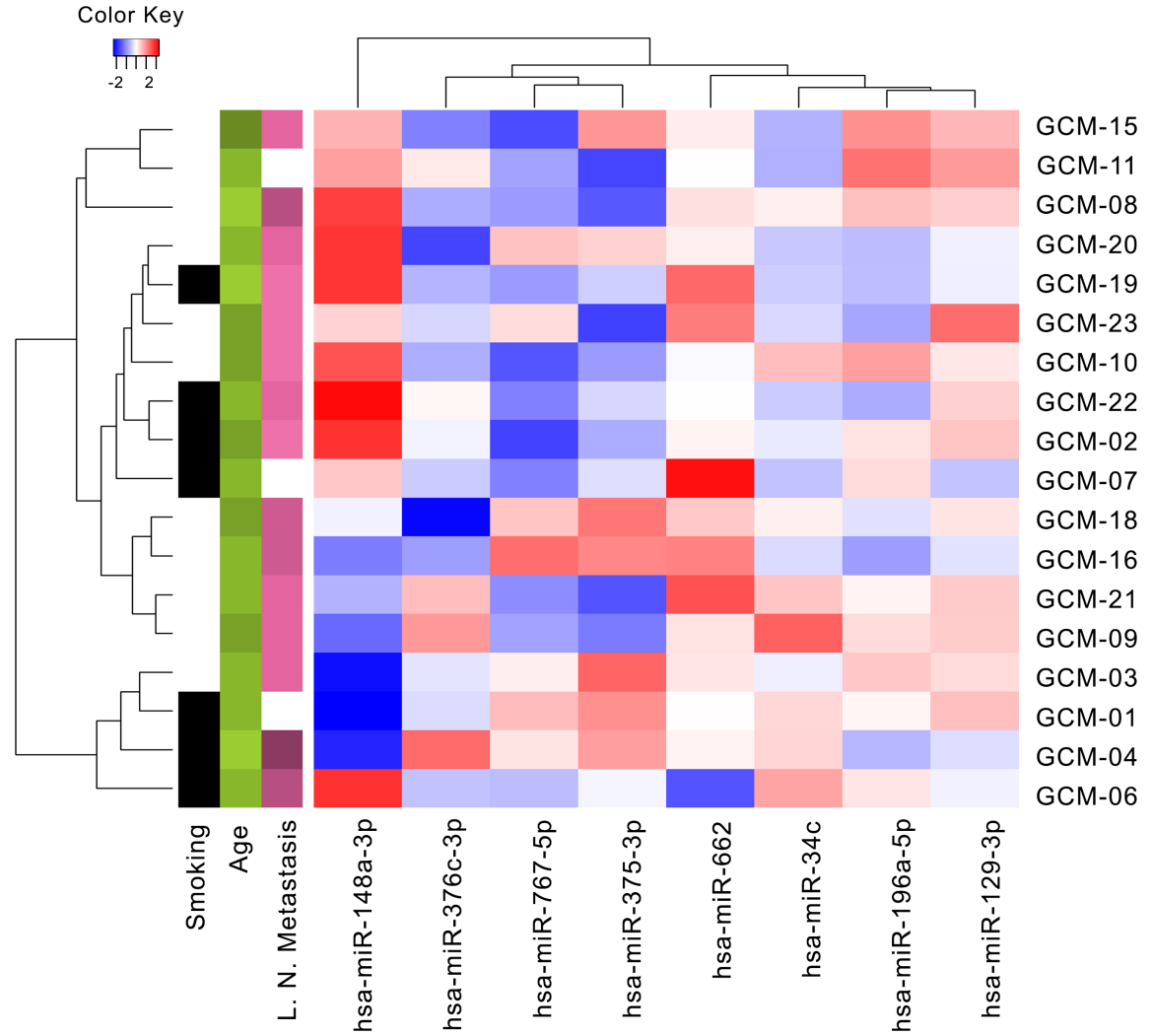

